\title{
VAI TRÒ CỦA CT-64 LÁT CĂT TRONG CHẦN ĐOÁN BỆNH TIM BẨM SINH
}

\author{
Dưong Phước Hùng ${ }^{*}$, Bùi Đúcc Phú* ${ }^{*}$ Hoàng Minh Lọi ${ }^{* *}$, \\ Lê Trọng Khoan ${ }^{*}$ *, Nguyễn Văn Thành ${ }^{*}$
}

\section{TÓM TẮT:}

Từ đầu năm 2009 Bệnh viện Trung ương Huế đã được trang bị máy CT-64 lát cắt, chúng tôi đã phát hiện nhiều trường hợp tim bẩm sinh phức tạp như tứ chứng Fallot, thất phải hai đường $\mathrm{ra}$, tuần hoàn bàng hệ chủ-phổi phức tạp, bất sản động mạch phổi có kèm thông liên thất, thất trái độc nhất, hẹp eo động mạch chủ, đứt đoạn động mạch chủ, phình động mạch vành, còn ống động mạch...Hầu hết các trường hợp được phẫu thuật đều có kết quả phù hợp với chẩn đoán.

Với độ phân giải từng phần cao và tái tạo hình ảnh 3 chiều, CT-64 lát cắt tim mạch thể hiện rất hiệu quả các cấu trúc giải phẫu và mối tương quan giữa chúng, ngay cả ở các trẻ nhỏ. CT-64 lát cắt tim mạch đặc biệt hữu ích để khảo sát hình ảnh của các vùng mà siêu âm tim không thể nhìn thấy rõ như các mạch máu lớn.

CT-64 lát cắt tim mạch là phương pháp khám xét nhanh và không xâm nhập, có thể chẩn đoán chính xác các bệnh tim bẩm sinh, khắc phục các hạn chế của siêu âm tim như cửa sổ âm khó khảo sát và cung cấp các thông tin cần thiết tổng thể cho phẫu thuật.

\section{ABSTRACT}

THE ROLE OF 64-MSCT IN THE DIAGNOSIS OF CONGENITAL HEART DISEASE

Since early 2009 Hue Central hospital has been equipped with 64-MSCT, we detected a number of complex congenital heart diseases such as tetralogy of Fallot, double outlet right ventricle, major aortopulmonary collateral shunts, pulmonary atresia with VSD, single left ventricle, aortic coartation, aortic interruption, aneurysm of coronary artery, patent ductus
arteriosus...Most of operated cases demontrated the good diagnostic correlation

With its superior spatial resolution and 3D imaging, cardiac 64-MSCT is excellent for demonstrating anatomic structures and their spatial relationships, even in small infants. Cardiac 64-MSCT particularly is useful for imaging regions not visualized well by echocardiography, such as the cardiac great vessels.

Cardiac 64-MSCT is the non-invasive and fast method that may precise currently the diagnosis of congenital heart disease, overcome the limit of echocardiography such as poor acoustic windows and provide the entire necessary information for operation.

\section{I. ĐẠTT VẤN ĐỀ}

Bệnh tim bẩm sinh (TBS) là bệnh khá thường gặp chiếm khoảng $1 \%$ số trẻ sơ sinh sống. Ở Mỹ có hơn 400.000 người mắc bệnh $\mathrm{TBS}$, trên 150.000 người không được chẩn đoán. Số bệnh nhân mắc bệnh TBS sống đến tuổi trưởng thành tăng lên nhờ sự phát triển của các phương tiện chẩn đoán hình ảnh giúp phát hiện bệnh sớm với độ chính xác cao và nhờ sự tiến bộ của các phương pháp phẫu thuật tim mạch. Siêu âm tim là phương tiện chẩn đoán đơn giản giúp phát hiện đa số trường hợp nhưng vẫn có giới hạn với bệnh TBS phức

(*) Trung tâm Tim mạch-Bệnh viện Trung uoong Hué (**) Bộ môn Chẩn đoán hình ảnh-Đại học Y Dươc Huế Người chịu trách nhiệm khoa hoc: GS.TS Bùi Đức Phú Email: buiducphu@gmail.com

Ngày nhận bài: 10/04/2013

Ngày Cho Phép Đăng: 18/04/2013

Phản Biện Khoa học: PGS.TS. Lê Ngọc Thành, GS.TS.Bùi Đúcc Phú 
tạp. CT-64 lát cắt là phương tiện chẩn đoán mới, được ứng dụng rộng rãi trong những năm gần đây trong lĩnh vực tim mạch, có tính năng kỹ thuật cao, không xâm nhập, cho kết quả nhanh, chính xác, giúp xác định rõ cấu trúc của tim và tương quan với các mạch máu lớn, nhằm định hướng điều trị sớm và thích hợp cho bệnh nhân.

\section{II. ĐỐI TƯợNG VÀ PHƯớng PHÁP NGHIÊN CỨU}

Bệnh nhân chẩn đoán bệnh TBS. Phương tiện: máy CT-64 Brilliance của Philips-Mỹ với các thông số kỹ thuật: $140 \mathrm{KV}, 350-450 \mathrm{~mA}$ và 120 $180 \mathrm{mAs}$. Collimation $0.5 \mathrm{~mm}$, bước bàn $0.5 \mathrm{~mm}$, thời gian quay $0.4 \mathrm{~s}$, độ dày lớp cắt $0,67 \mathrm{~mm}$, khoảng tái tạo $0,33 \mathrm{~mm}$. Tái tạo $3 \mathrm{D}$ : MPR, MIP và VRT. Máy bơm hai nòng Medrad Stellant, thuốc cản quang Ultravist, thuốc bơm 1-1,5ml/kg cân nặng, tốc độ 3$5 \mathrm{ml} / \mathrm{s}$ sau đó tiêm Bolus $40 \mathrm{ml}$ nước muối sinh lý $0,9 \%$. Nghiên cứu tiến cứu, mô tả.

\section{KẾT QUẢ}

Từ 01-2009 đến 03-2012 có 110 bệnh nhân mắc bệnh TBS được chụp CT-64 lát cắt tim tại Trung tâm tim mạch Bệnh viện Trung ương Huế, trong đó gồm có các bệnh như tứ chứng Fallot, thất phải hai đường ra, tuần hoàn bàng hệ chủ-phổi phức tạp, bất sản động mạch phổi có kèm thông liên thât, thất trái độc nhất, hẹp eo động mạch chủ, đứt đoạn động mạch chủ, phình động mạch vành, còn ống động mạch...

Hầu hết các trường hợp được phẫu thuật đều cho thấy kết quả chẩn đoán trước và sau mổ hoàn toàn phù hợp. Số bệnh nhân còn lại không được phẫu thuật do tính chất phức tạp của bệnh hoặc do điều kiện kinh tế không cho phép.

1. Tuổi và giới: 110 bệnh nhân TBS được chụp CT-64 lát cắt tim mạch, 70 nam (63.6\%) và 40 nữ $(36,4 \%)$. Tuối trung bình $18,64 \pm 9.08$; thấp nhất 4 tháng tuổi, cao nhất:51 tuổi.

\section{2. Đặc điểm các bệnh tim bẩm sinh}

\begin{tabular}{|l|c|c|}
\hline \multicolumn{1}{|c|}{ Bệnh TBS } & $\mathbf{n}$ & $\mathbf{\%}$ \\
\hline Tứ chứng Fallot/CÔĐM & $25 / 5$ & 22,72 \\
\hline $\begin{array}{l}\text { Thất phải hai đường ra/TLT/Bất } \\
\text { sản ĐM phổi trái }\end{array}$ & $10 / 10 / 5$ & 9,10 \\
\hline Tâm thất độc nhất/CÔĐM & $5 / 2$ & 4,54 \\
\hline APSO/CÔĐM & $15 / 10$ & 13,64 \\
\hline Dò động mạch vành/CÔĐM & $5 / 1$ & 4,54 \\
\hline $\begin{array}{l}\text { Hẹp eo ĐMC/CÔĐM/phình gốc } \\
\text { ĐM dưới đòn phải }\end{array}$ & $25 / 5 / 2$ & 22,72 \\
\hline Đứt doạn quai ĐMC/TLT/CÔĐM & $20 / 15 / 4$ & 18,20 \\
\hline CÔĐM & 5 & 4,54 \\
\hline
\end{tabular}

\section{BÀN LUẬN}

Tim bẩm sinh chiếm tỉ lệ thấp khoảng $1 \%$ tổng số trẻ sơ sinh còn sống, phần lớn phát hiện sau sinh với các triệu chứng: tím khi gắng sức, mệt mỏi, ăn uống kém, chậm phát triển thể chất và âm thổi ở tim. Một số trường hợp phát hiện tình cờ, thường phối hợp nhiều tật và có tuần hoàn bàng hệ rất phức tạp. Siêu âm tim phát hiện đa số trường hợp nhưng có hạn chế như đối tuần hoàn bàng hệ phổi chủ phức tạp, dò ĐM vành, tương quan giữa tim với mạch vành dò hoặc với các mạch máu lớn, đứt đoạn quai ĐMC siêu âm tim không phát hiện được chỗ cắm ĐMC xuống.

Tái tạo đa bình diện MPR theo các mặt phẳng khác nhau trong không gian ba chiều (mặt phẳng ngang, mặt phẳng trán và mặt phẳng dọc giữa).

Tái tạo ba chiều theo thể tích khối VRT khảo sát nhiều hướng giúp thấy tương quan của tim và mạch máu lớn trong những trường hợp phức tạp.

\section{Bệnh TBS chia làm ba nhóm:}

1. Nhóm có khả năng gây tím gồm: TLN, TLT và CỐĐM. TLT là một bệnh TBS thường gặp nhất chiếm khoảng $30 \%$ các bệnh TBS. Hầu hết các trường hợp TLT thường độc lập, nhưng có khoảng 20\% TLT có kết hợp với các bất thường khác. Tùy thuộc vào kích thước và vị trí của lỗ thông. Đa số TLT đóng tự nhiên trong những năm đầu của cuộc sống. Các vấn đề chức năng của TLT có liên quan với kích thước của 
dòng chảy trái-phải, ngay cả có thể tiến triển thành hội chứng Eisenmenger với tăng áp phổi nặng và đảo ngược dòng chảy. CT đa lát cắt không phải là kỹ thuật chọn lựa để phát hiện và đánh giá TLT. Nhưng TLT là dấu hiệu thường hay gặp kết hợp với các khiếm khuyết tim bẩm sinh khác được phát hiện trên $\mathrm{CT}$ đa lát cắt. Bất thường này có thể thấy rõ trên chụp CT-64 lát cắt với kỹ thuật tái tạo nằm ngang theo trục dài và hình ảnh tái tạo theo mặt phẳng trán coronal.

2. Nhóm TBS có tím gồm: tứ chứng Fallot, teo van ba lá, thân chung động mạch, một thất độc nhất, thất phải hai đường ra, TM phổi đổ về bất thường hoàn toàn và chuyển vị đại động mạch. Tứ chứng Fallot là bệnh TBS có tím hay gặp nhất bao gồm tứ chứng: ĐMC cưỡi ngựa lên vách liên thất, TLT, hẹp đường ra thất phải (thường là hẹp phễu $M$ phổi) và phì đại thất phải. Thường đi kèm với van phổi 2 lá, hẹp ĐM phổi trái, cung ĐMC đảo ngược qua bên phải, các bất thường của động mạch vành và của khung xương lồng ngực. Nếu có kết hợp với TLN thì được gọi là ngũ chứng Fallot. Tam chứng Fallot bao gồm hẹp ĐM phổi, phì đại thất phải và còn lỗ bầu dục. CT-64 lát cắt với kỹ thuật tái tạo bán phần theo mặt phẳng trán vuông góc với vách liên thất có thể thấy rõ $\mathrm{TLT}, \mathrm{DMC}$ cởi ngựa lên vách liên thất và hẹp phễu ĐM phổi. Chuyển vị đại động mạch là bệnh TBS có tím hay gặp thứ hai với tần suất khoảng 315 trên một triệu trẻ sinh ra sống. Đây là nhóm bất thường có đặc điểm bất tương hợp các buồng timđại động mạch. Trong trường hợp chuyển vị hoàn toàn $(\mathrm{D}-\mathrm{TGA})$ thì ĐMC nằm trước xuất phát từ phía trước thất phải và ĐMP xuất phát từ phía sau thất trái. Vị trí của các tâm nhĩ, tâm thất và các van tim bình thường. Điều này tạo ra hai vòng tuần hoàn độc lập nhau với vài nối thông cần thiết để duy trì sự sống. Bệnh nhân có kết hợp với còn lỗ bầu dục, CỐĐM hoặc TLT hoặc với các bất thường tim bẩm sinh phức tạp hơn. CT-64 lát cắt cho phép đánh giá chính xác vị trí và hình thái các đại động mạch tương quan với cấu trúc tổng thể của tim.
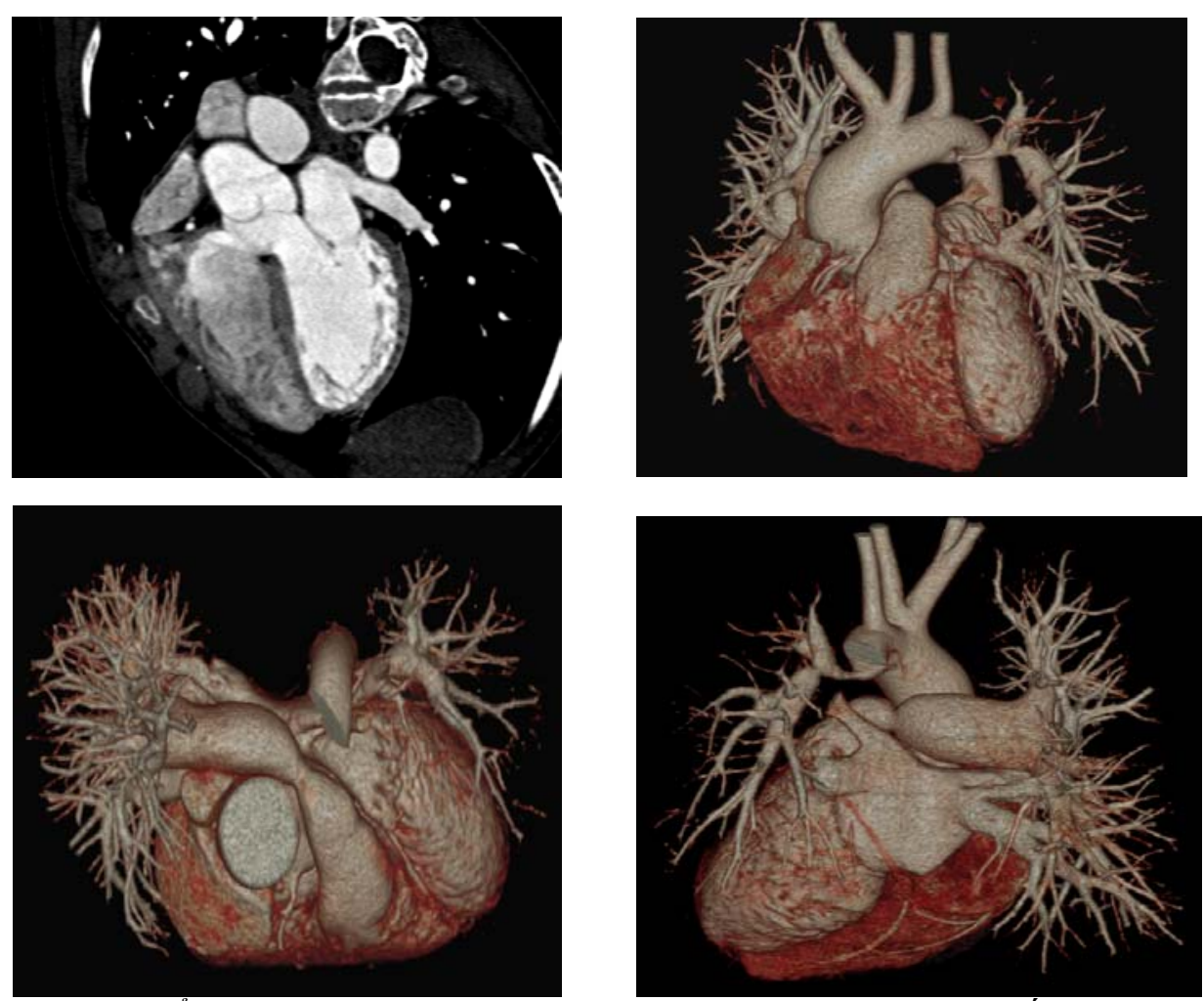

Hình 1: BN Nũ 13 tuổi: Tứ chứng Fallot với ĐMC cữ̛i ngụa khoảng 45\%, thất phải dãn khoảng 40mm, phễu ĐM phổi hẹp khoảng $8 \mathrm{~mm}$, lỗ TLT khoảng $15 \mathrm{~mm}$. ĐM phổi trái không xuất phát tù thân ĐM phổi mà tiếp nối với $C \hat{O} Đ M$. 

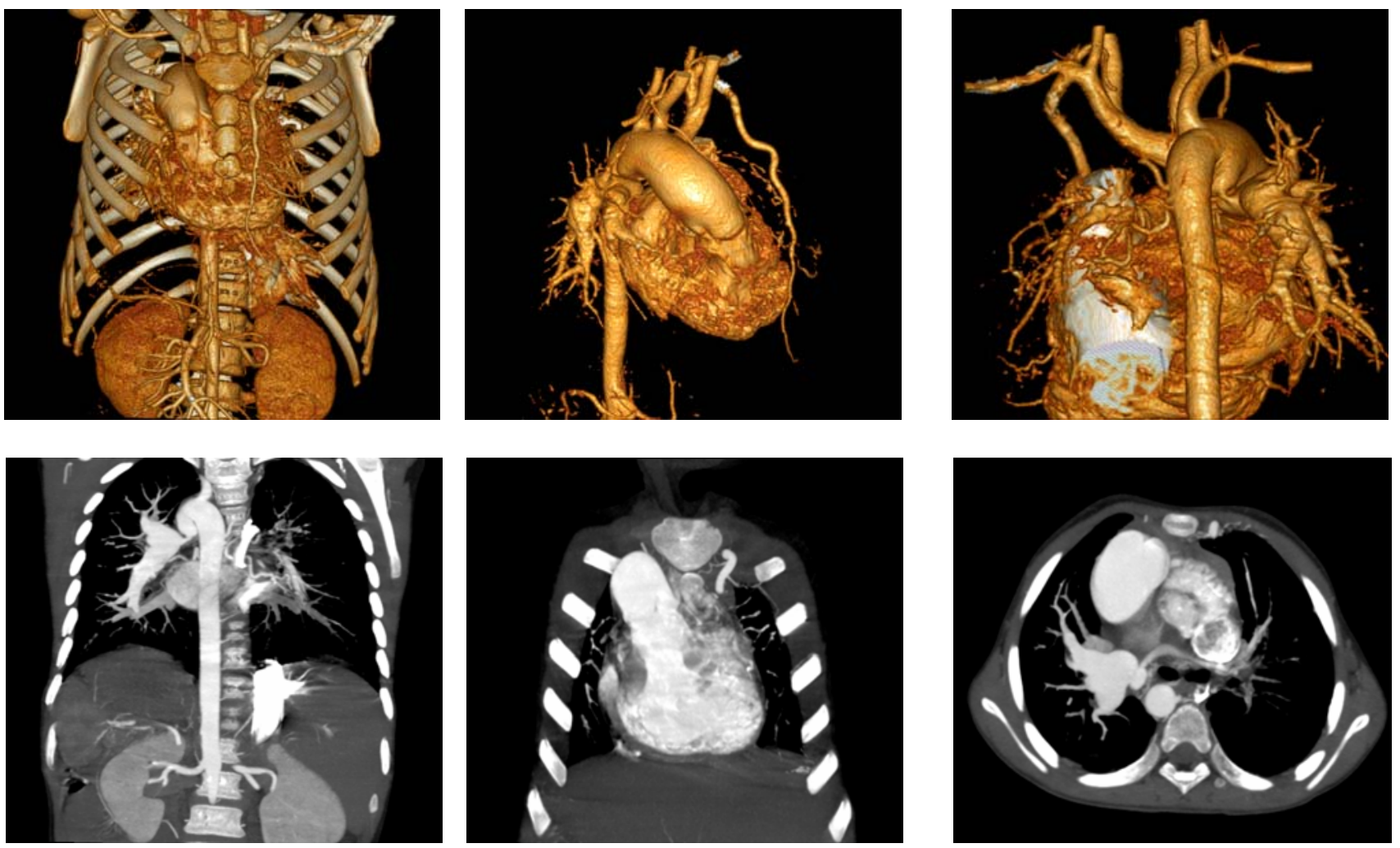

Hình 2: BN Nam 7 tuổi: Đảo ngược phủ tạng hoàn toàn, thất trái độc nhất, bất sản hoàn toàn thân ĐM phổi,

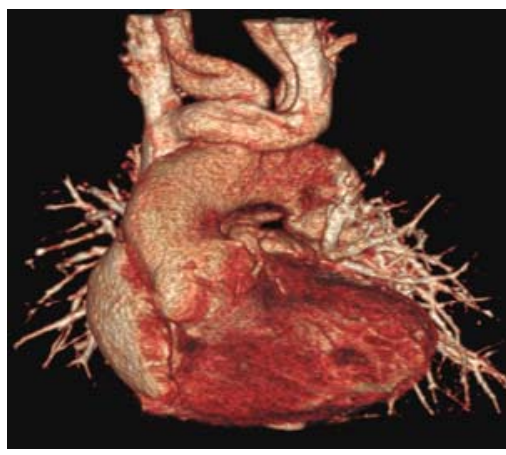
CÔĐM, giảm sản ĐM phổi trái.
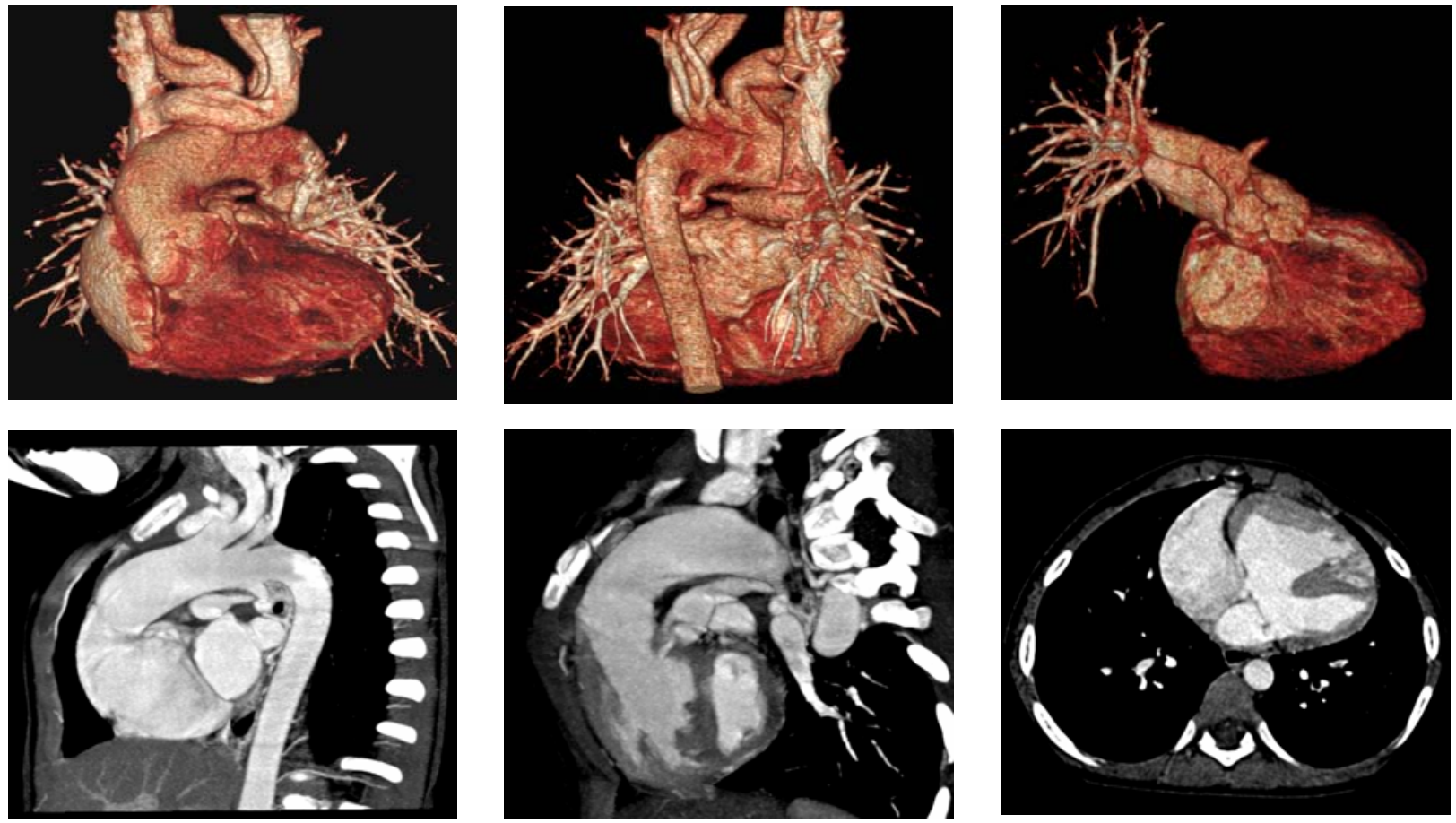

Hình 3. BN Nam 3 tuổi: Thất phải hai đưòng ra, ĐMC nằm ở bên phải và ra phía truớc, ĐM phổi nằm ở bên trái và ra sau, TLT, hẹp thân chung ĐM phổi, bất sản ĐM phổi trái. Nhánh ĐM phổi trái khác xuất phát tù quai ĐMC cạnh trước eo và hẹp nhiều ở đoạn giũua. Nhiều nhánh tuần hoàn bàng hệ. 

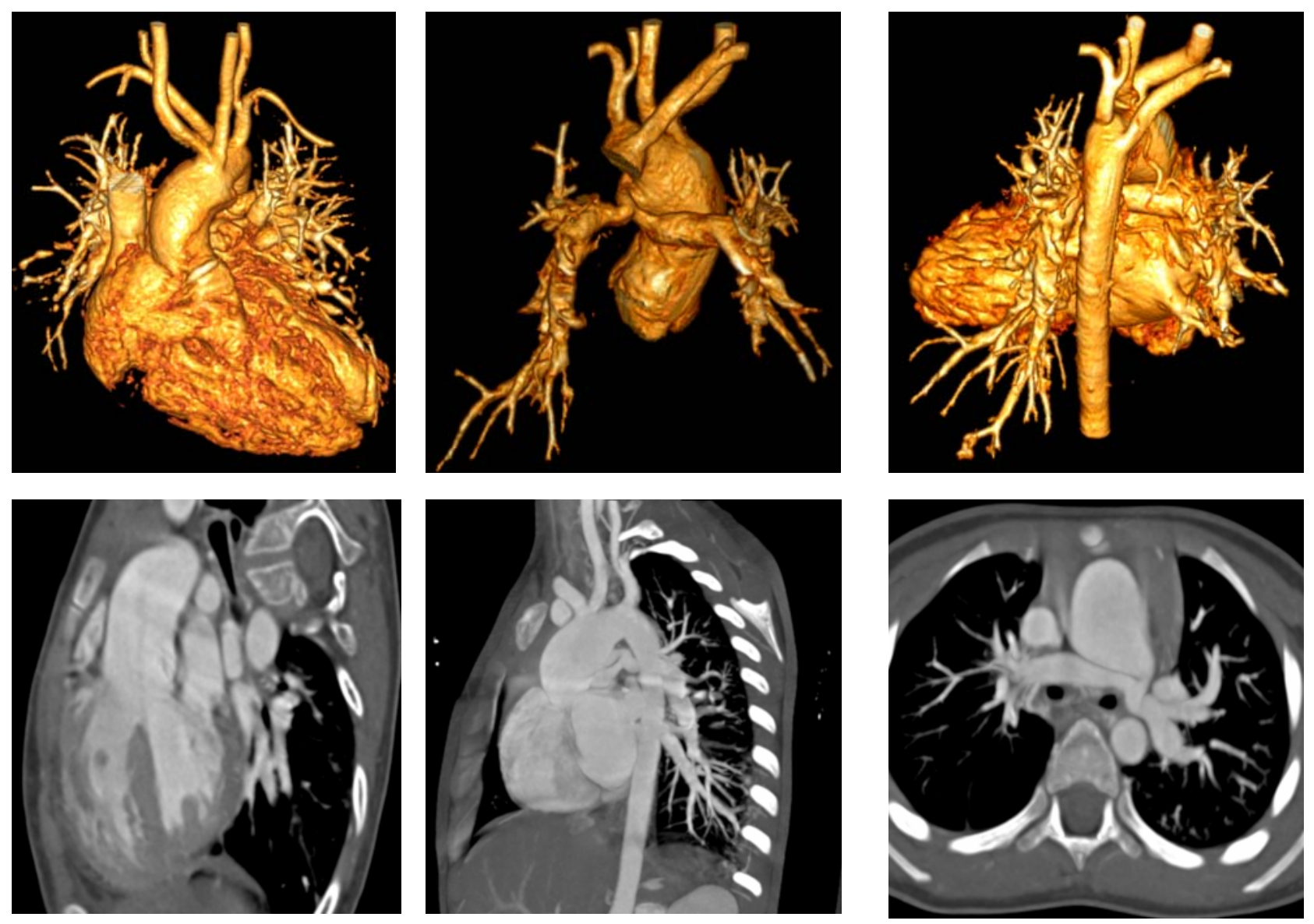

Hình 4. BN Nũ̃ 2 tuổi: APSO Type III, CÔĐM, bất thường vị trí các nhánh ĐM lên

3. Nhóm không có tím gồm: hẹp eo ĐMC chiếm khoảng $8 \%$ tổng số trẻ mắc bệnh TBS sống, có tiên lượng không tốt, tuổi thọ trung bình khoảng 35 tuổi. Hẹp eo ĐMC là bất thường hẹp bẩm sinh ĐMC. Ở trẻ em có dạng giảm sản hình ống ảnh hưởng trên một đoạn dài của đoạn xa ĐMC ngực đến gốc của thân động mạch cánh tay đầu và có thể hẹp mức độ nhiều ở đoạn gần của $\mathrm{DMC}$ xuống đến vị trí của dây chằng động mạch. Vì được chẩn đoán sớm khi còn trẻ nhỏ nên $\mathrm{CT}$ đa lát cắt thường được sử dụng chủ yếu để theo dõi sau sửa chữa phẫu thuật. Ở người lớn có dạng hẹp eo ĐMC khu trú, vị trí hẹp ở ngay sau ĐM dưới đòn trái hoặc vị trí dây chằng động mạch. Ở người lớn, được chẩn đoán trễ, thường là dấu hiệu phát hiện tình cờ và ít có kết hợp với các bất thường tim khác. Triệu chứng lâm sàng ở người lớn biểu hiện là tăng huyết áp, phình tách động mạch, nhồi máu não, suy tim hoặc viêm nội tâm mạc. CT-64 lát cắt có thể cung cấp đầy đủ thông tin về vị trí và mức độ hẹp trên các hình ảnh tái tạo $3 \mathrm{D}$ theo kỹ thuật VRT, MIP và MPR. Các dấu hiệu gợi ý hẹp eo ĐMC trên CT-64 lát cắt: ĐM dưới đòn trái xuất phát ở phía sau tại vùng tiếp nối với ĐMC xuống, dấu hiệu này gặp trong hơn $70 \%$ trường hợp, hoặc dấu hiệu dãn lớn ĐM liên sườn hoặc các ĐM vú. Tuần hoàn bàng hệ đặc biệt tăng nhiều nếu cung ĐMC bị tắc. CT-64 lát cắt còn đánh giá chính xác các vòng nối tuần hoàn bàng hệ như dưới đòn, vú trong, liên sườn, thượng vị... trên các hình ảnh tái tạo theo thể tích khối VRT. Dấu hiệu dãn sau hẹp thường hay gặp. Tái tạo hình ảnh theo trục dọc hoặc ba chiều cho phép đánh giá chính xác mức độ hẹp. Cần phân biệt với giả hẹp eo ĐMC, là sự kéo dài kèm xoắn của ĐMC tại vị trí của dây chằng động mạch. Trong một số trường hợp có thể có kết hợp với phình mạch của các nhánh trên quai ĐMC ngực. 

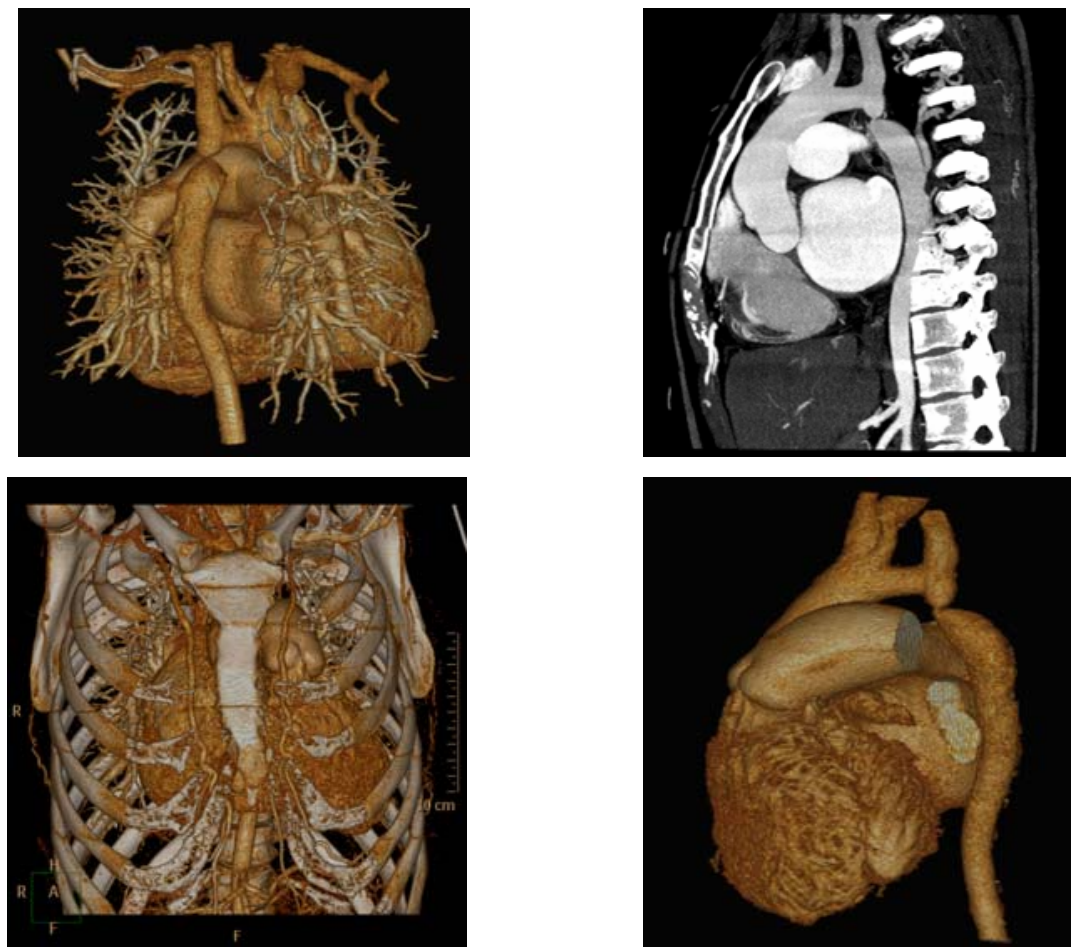

Hình 5: BN Nam 24 tuổi: Hẹp eo ĐMC ngục mức độ nặng, vị trí hẹp cạnh ngay sau ĐM dưới đòn trái, ĐK hẹp nhất khoảng $2 \mathrm{~mm}$. Dấu tăng áp phổi nặng: có nhiều tuần hoàn bàng hệ ở vùng trung tâm và ngoại vi của lồng ngục.
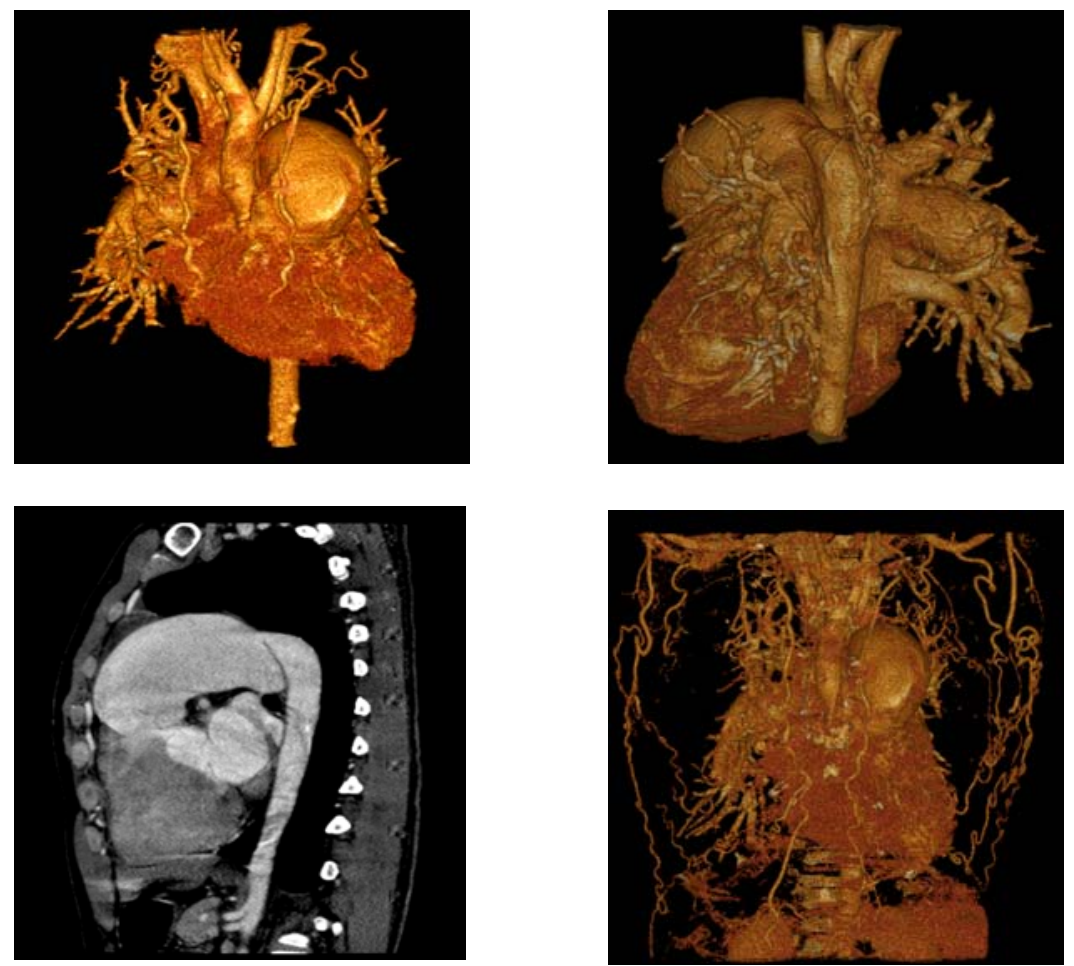

Hình 6: BN nam 26 tuổi: Đứt đoạn hoàn toàn phần ĐMC duới eo ngay sau ĐM dưới đòn trái (Type A). ĐMC xuống tiếp nối với CÔĐM. TLT lớn dưới van ĐMC và ĐMP. Tăng áp ĐMP nặng. 

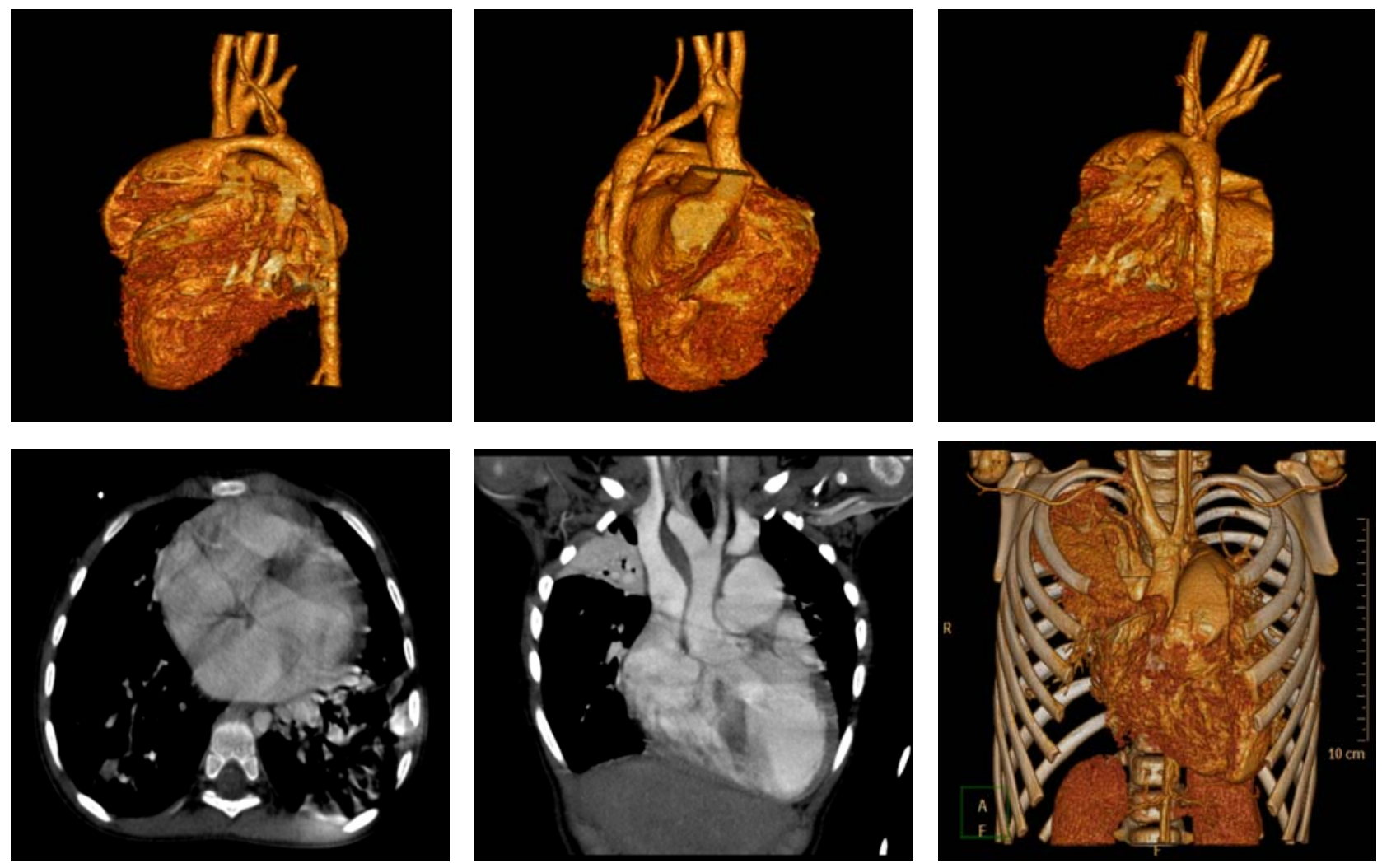

Hình 7: BN nũ 5 tuổi: Đưt đoạn hoàn toàn phà̀n ĐMC sau ĐM cảnh chung trái và trước eo (Type B). ĐMC xuống tiếp nối với CỐĐM. Nhánh ĐM bất thường nối ĐMC xuống với thân ĐM cánh tay đàu. TLT lớn nằm ngay dưới van ĐMC. Tăng áp lực ĐM phổi nặng.

\section{KẾT LUẬN}

CT-64 lát cắt là phương pháp chẩn đoán hình ảnh hữu ích trong chẩn đoán bệnh tim bẩm sinh. Đây là phương pháp chẩn đoán nhanh, không xâm nhập, có độ chính xác cao, giúp đánh giá tổng thể cấu trúc của tim trước phẫu thuật và khắc phục được một số hạn chế của siêu âm tim trong các trường hợp tim bẩm sinh phức tạp do cửa sổ âm khó khảo sát và không thể nhìn thấy rõ toàn bộ các mạch máu lớn.

\section{TÀI LIỆU THAM KHẢO}

1. Becker CR, Ohnesorge BM, Schoepf UJ et al. (2000), "Current development of cardiac imaging with multidector-row CT” Eur J Radiol 36: 97-103.

2. Hoffman J I, Kaplan S (2002), "The incidence of congenital heart disease", J Am Coll Cardiol 39: 1890-1900.

3. Kaemmerer H, Stern H, Fratz $\mathbf{S}$ et al. (2000), "Imaging in adults with congenital cardiac disease". Thorac Cardiovasc Surg.
4. Kawano T, Ischii M, Takagi J et al. (2000), "Three-Dimensional helical computed tomographic angiography in neonates and infants with complex congenital heart disease" Am Heart $J$ 139: 654-660.

5. M. Prokop, M.Galanski, A.J. van der Molen (2003), "Spiral and multislice computed tomography of the body" The heart, 761-794.

6. Murray G.Baron et al (2004), "Congenital heart disease in the adult", Radiol clin N Am 42: 675-690.

7. Ohnesorge BM, Becker CR, Flohr TG, Reiser MF (eds), (2005), "Multi-slice CT in cardiac imaging: Technical principles, imaging protocols, clinical indications and future perspective" New York, Springer.

8. R.C. Gilkeson, Leslie Ciancibello and Kenneth Zahka (2002), "Multidetector CT evaluation of congenital heart disease in pediatric and adults patients". 